\title{
FOOD HABIT AMONG ELEMENTARY SCHOOL CHILDREN IN URBAN BOGOR
}

\author{
Evy Damayanthi ${ }^{1 *}$, Cesilia Meti Dwiriani ${ }^{1}$, Lilik Kustiyah ${ }^{1}$, and Dodik Briawan ${ }^{1}$ \\ 1 Department of Community Nutrition, Faculty of Human Ecology, Bogor Agricultural University, \\ Bogor, West Java, Indonesia 16680. \\ * Corresponding Author: Department of Community Nutrition, Faculty of Human Ecology, \\ Bogor Agricultural University, Bogor, West Java, Indonesia 16680. Telp: 0251-8621258; \\ Facs: 0251-8622276, Email: evyimam@yahoo.com
}

\begin{abstract}
Food habit strongly predicts individual nutritional status. It is largely influenced by family food habit and family socioeconomic, partly by nutrition education learning in the school. Objectives of this study were to analyze elementary school children eating habit and examine whether it relates to family socioeconomic and nutritional status. One hundred elementary school children, and their mother, from one school in urban Bogor were chosen purposively according to SIBERMAS Program criteria (i.e. grade $4^{\text {th }}$ and $5^{\text {th }}$, morning school, having UKS program and not having canteen). Self administered, structured pre-coded questionnaire were used to collect the data. Nutritional status was assessed using weight and height, and body mass index for age (BAZ) and height for age (HAZ) were then calculated using AnthroPlus software developed by WHO (2009). School children were 8-11 years old (mean $9.37 \pm$ 0.66 years), more girls (54\%), and mostly had normal nutritional status using both indexes (72\% for BAZ and $95 \%$ for HAZ). School children were commonly from middle class as indicated by father education (sarjana) and mother (senior high school). Almost all school children (99\%) knew breakfast was important and $81 \%$ of them ate breakfast. Only 32\% school children brought lunch box everyday although $92 \%$ stated their habit to bring lunch box to school. Buying snack in school was also common among school children. Generally school children ate rice 3 times a day $(2.95 \pm 0.97)$ with fish, meat, chicken $(2.47 \pm 1.14)$, tempe and tofu $(2.22 \pm 1.10)$, vegetables $(2.25 \pm 0.76)$ and fruits $(2.37 \pm 1.31)$. There was a tendency overweight and obese school children eat more rice although statistically not significant. On average, school children drank milk more than twice daily $(2.34 \pm 0.98)$, plain water more than 7 glasses daily $(7.34 \pm 4.10)$, exercise 3 times weekly $(3.02 \pm 2.16)$ and no difference were observed between nutritional status and family socioeconomics. School children food habit were strongly supported by mother behavior especially in providing breakfast, lunch box and guiding their children in choosing snack food. School children from middle class in urban Bogor had relatively good food habits which were supported by mother behavior. This study found no relationship between family socioeconomic and nutritional status on school children food habit.
\end{abstract}

Key words: food habit, nutritional status, elementary school children.

\section{INTRODUCTION}

In early 1950's, government introduce a slogan named 4-healthy-5-perfect to guide people to consumed nutritious foods to achieve better nutritional status. Globalization era has influenced community lifestyle and resulting in gradually changing in food habit which also affect trend of nutrition and health problems. Along with lifestyle changing and the development of science, in 1995, slogan of 4-healthy 5 perfect is revised to become balanced dietary guideline. The guideline provides information on the quantity and the balance of food intake along with advices for healthy life style, such as taking 8 glasses of drinking water daily, doing regular exercise, using iodized salt, limiting cigarette smoking and alcohol drinking and reading the label before buying packed of processed food. Yet, after more than a decade, the new guideline was very little acknowledged and improperly understood. For this reason, we develop activity, as part of multicenter study, to analyzed elementary school children knowledge, attitude and practices on balance diet in order to develop a model of information, education and communication (IEC) for intervention. We using the data to assess school children eating habit and examine whether it relates to family socioeconomic and nutritional status. 


\section{METHOD}

The design of this study is a cross sectional study and is a part of 10 similar multicenter studies. The study was conducted in two elementary public schools at urban Bogor, West Java. One hundred elementary school children, and their mother, from one school were chosen purposively according to SIBERMAS Program criteria (i.e. grade $4^{\text {th }}$ and $5^{\text {th }}$, morning school, having UKS program and not having canteen). Data on school children food habits and mother practices on preparation of food for their children were colected using self administered and structured pre-coded questionnaire. Mother practices in dealing with children food were also collected using self administered questionnaire.

Nutritional status of the school children were assessed using weight and height. Body weight was measured by digital scale (BOSO) with precision of $0.1 \mathrm{~kg}$, stature was measured using microtoise with precision of $0.1 \mathrm{~cm}$. Weight for age (WAZ) only calculated for those aged 8-10 years, while body mass index (BMI) for age (BAZ) and height for age (HAZ) were calculated for all school children. Those indexes were calculated using AnthroPlus Software developed by WHO (2009).

\section{RESULT AND DISCUSSION}

\section{Elementary School Children Characteristics}

The age of one hundred school children used in this study are ranged between 8 and 11 years old (mean $9.37+0.66$ years) and more girls $(54 \%)$. Proportion of grade $4^{\text {th }}$ and $5^{\text {th }}$ is equal, each are 50 school children. School children commonly from middle class as indicate by father education (undergraduate) and mother (senior high school). The distribution of elementary school children by age, gender, and father and mother education is presented in Table 1.

For those school children aged 8-10 years $(n=59), 88 \%$ are normal nutritional status, and $12 \%$ underweight. Using BAZ and $\mathrm{HAZ}$, most of the school children have normal nutritional status ( $72 \%$ for BAZ and $95 \%$ for $\mathrm{HAZ}$ ), and using BAZ there are $14 \%$ of school children categorized as thin, 11\% overweight and 3\% obese. Meanwhile according to HAZ index there are $5 \%$ of school children stunted. The distribution of BAZ and HAZ indexes for all school children and according to gender presented in Figure 1, 2, and 3. Compare to
Riskesdas data (MOH, 2007), the prevalence of thinness and overweight of our school children are lower than national, urban and West Java Province figure. Figure 2 show our school children data have wider curve, indicating a same proportion of those who classify as thin and overweight/obese. Figure 3 show more females students classify as stunted children. Figure 4 show the mean of z-scores of our school children data are in the normal range.

Table 1. Distribution of School Children by Age, Gender, and Parents Education

\begin{tabular}{cc}
\hline \multicolumn{1}{c}{ Characteristics } & $\%$ \\
\hline Age (year) (9.37 \pm 0.66) & 8 \\
8 & 49 \\
9 & 41 \\
10 & 2 \\
11 & \\
Gender & 46 \\
Male & 54 \\
Female & \\
Family member & 63.5 \\
s 4 & 36.5 \\
$\geq 5$ & \\
Father Education & 6.3 \\
Junior high school & 28.1 \\
Senior high school & 12.5 \\
Diplom & 42.7 \\
Undergraduate & 9.4 \\
Postgraduate & \\
Mother Education & 1.0 \\
Elementary & 2.0 \\
Junior high school & 44.8 \\
Senior high school & 24.0 \\
Diplom & 25.0 \\
Undergraduate & 3.1 \\
Postgraduate &
\end{tabular}

\section{School children Practices on Food}

Table 2 shows that almost all school children know breakfast is important and $81 \%$ of them eat breakfast every morning. Only $32 \%$ school children bring lunch box everyday although $92 \%$ state their habit to bring lunch box to school. Buying snack in school is also common habit among almost all school children (95\%). Chicken, egg and fish were consumed frequently/everyday by more than $60 \%$ school children, while meat only by $42 \%$. More than $90 \%$ student drink milk frequently/everyday, more than $80 \%$ eat green vegetables and orange/red-colored fruits frequently/everyday, but only 33 school children state that they were eat more rice than the other food. Those figure shows that the school children have relatively good practices in dealing with food such as breakfast every morning at home eat variety of food for their meals (i.e. rice with side dish, vegetables and fruit) although they eat less rice and frequently buy snack food at school. 


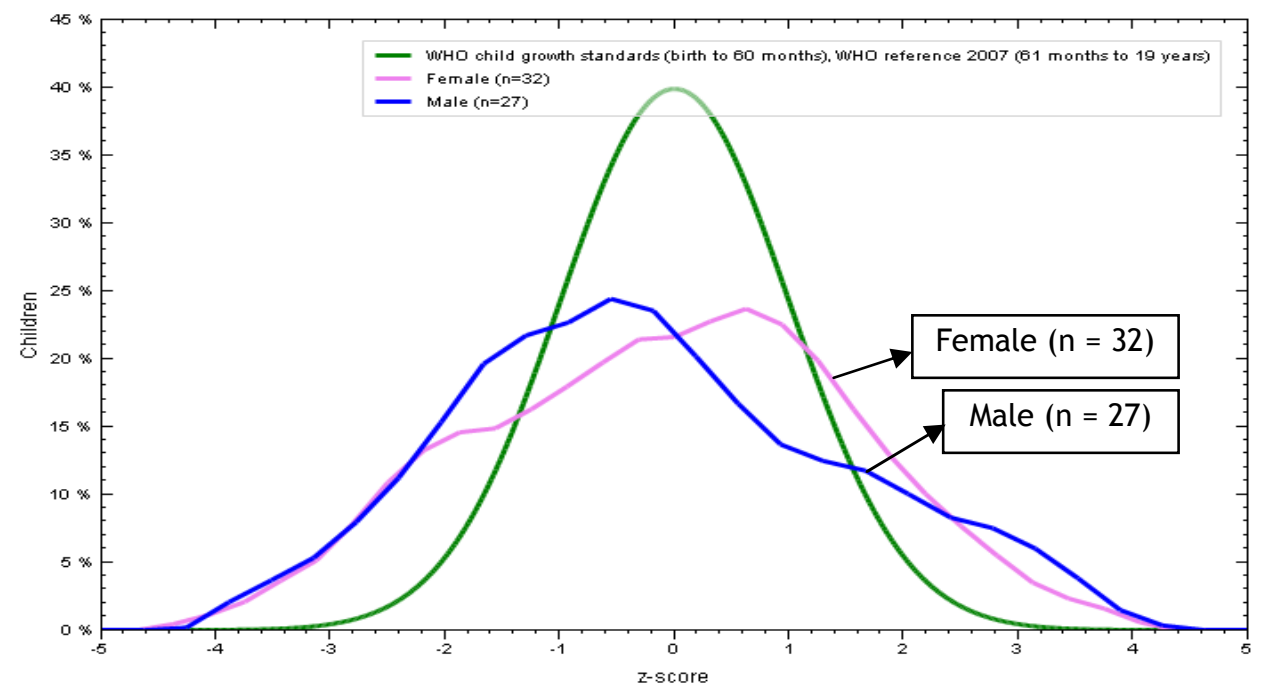

Figure 1. Z-score for 8-10 Years School Children with Indicator Weight for Age

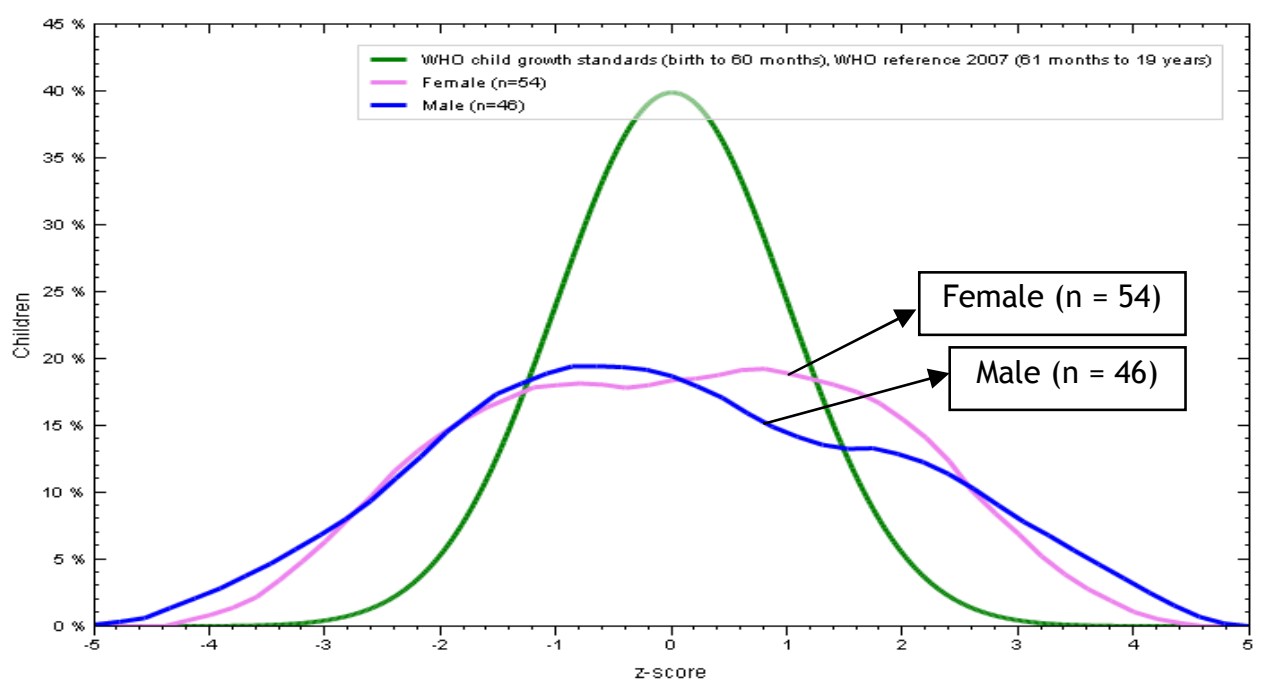

Figure 2. Z-score for All School Children with Indicator Body Mass Index for Age by Gender

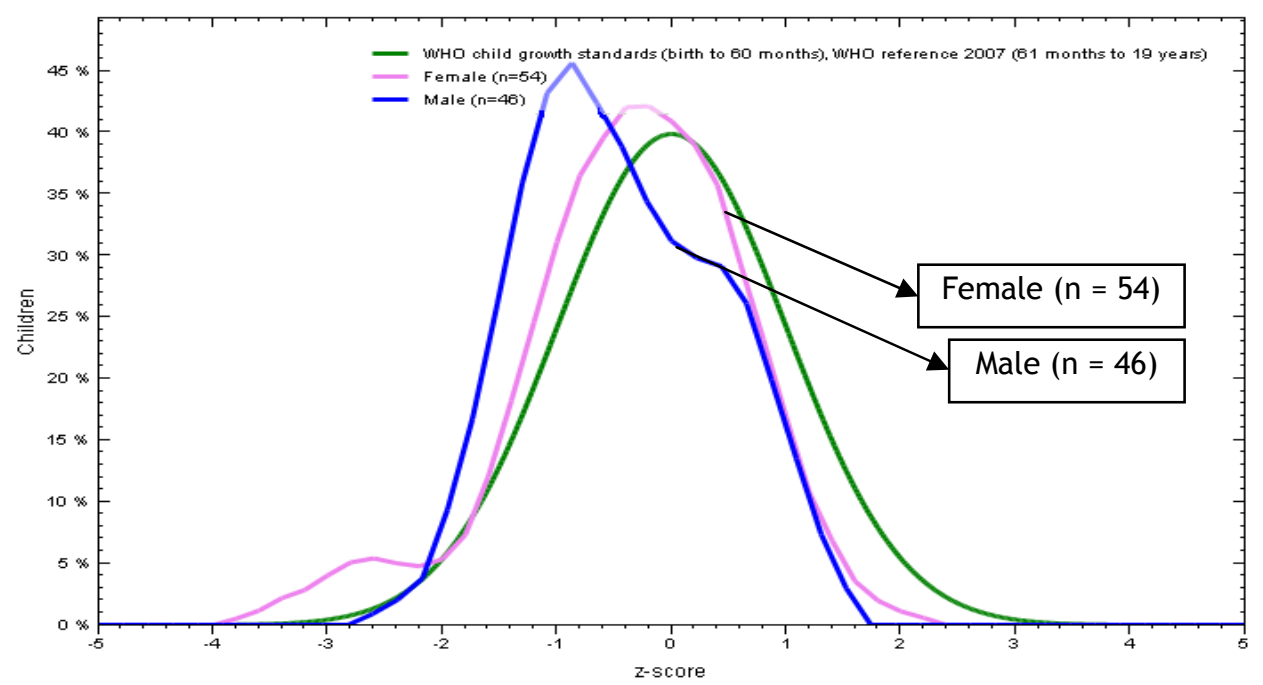

Figure 3. Graphic Z-score for All School Children with Indicator Height for Age 


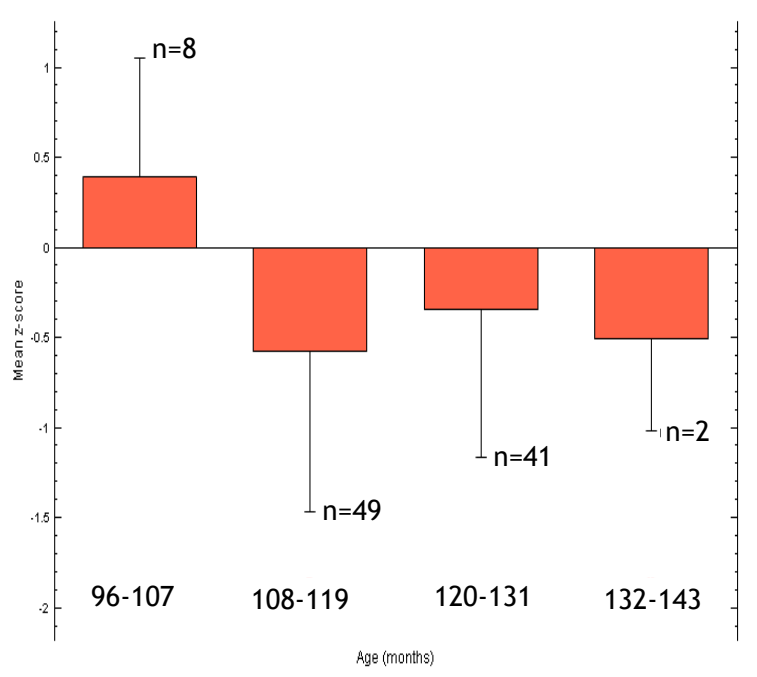

(a)

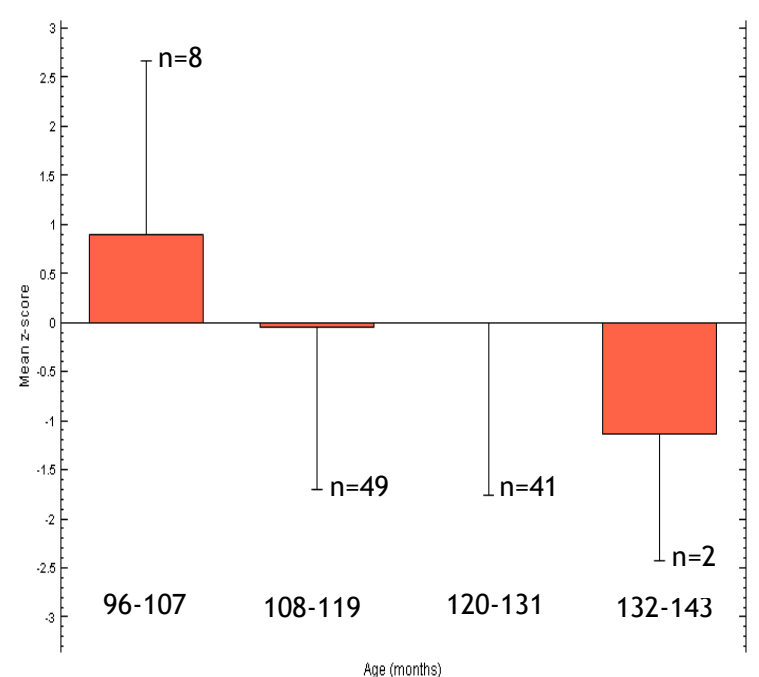

(b)

Figure 4. Mean of BAZ (a) and HAZ (b) by Age

Table 2. Practice of Schoolchildren $(n=100)$

\begin{tabular}{lc}
\hline \multicolumn{1}{c}{ Question } & $\begin{array}{c}\text { Yes } \\
\text { answer (\%) }\end{array}$ \\
\hline Breakfast everyday & 81 \\
Bring food from home everyday & 32 \\
Bring food from home frequently & 60 \\
Buy food frequently at school & 95 \\
I buy food (JAJAN) everyday & 21 \\
Eat egg, frequently/everyday & 65 \\
Eat chicken, frequently/everyday & 80 \\
Eat meat, frequently/everyday & 42 \\
Eat fish, frequently/everyday & 69 \\
Drink milk, frequently/everyday & 91 \\
Eat green vegetables, frequently/everyday & 83 \\
Eat orange /red-coloured fruits, & 83 \\
frequently/everyday & 33 \\
Eat rice more than others &
\end{tabular}

When we asked to quantify the school children eating habits, generally s stated they are eating rice 3 times a day $(2.95 \pm 0.97)$ with fish, meat, chicken $(2.47 \pm 1.14)$, tempe and tofu $(2.22 \pm 1.10)$, vegetables $(2.25 \pm 0.76)$ and fruits $(2.37 \pm 1.31)$ (Table 3$)$.
According to school children nutritional status, there is a tendency of overweight and obese school children eat more rice than the normal one although statistically not significant. Tabel 4 also shows that on average, students drink milk more than twice daily $(2.34 \pm$ $0.98)$, plain water more than 7 glasses daily $(7.34 \pm 4.10)$ and exercise 3 times weekly (3.02 \pm 2.16$)$. No differences were observed on school children practice between nutritional status and family socioeconomics.

\section{Mother Practices}

School children food habit are strongly supported by mother behavior especially in providing breakfast, lunch box and giving vegetables everyday to their children meal and guiding their children in buying snack food (Table 4). The detail of mother advices regarding buying snack food is presented in Table 5 .

Table 3. Mean of Food Frequency Consumption in School Children

\begin{tabular}{clc}
\hline No & \multicolumn{1}{c}{ Questions } & Mean \pm Sdev \\
\hline 1 & How many times do you eat rice daily? & $2.95 \pm 0.968$ \\
2 & How many times do you eat vegetables daily? & $2.25 \pm 0.757$ \\
3 & How many times do you eat fruits daily? & $2.37 \pm 1.308$ \\
4 & How many times do you eat meat/ fish/chicken/egg daily? & $2.47 \pm 1.141$ \\
5 & How many times do you eat tempe/tofu daily? & $2.22 \pm 1.097$ \\
6 & How many glassess do you drink milk daily? & $2.34 \pm 0.977$ \\
7 & How many glassess do you take sweet drink daily? & $1.55 \pm 0.968$ \\
8 & How many glassess do you drink water daily? & $7.34 \pm 4.098$ \\
9 & How many times do you take exercise weekly? & $3.02 \pm 2.155$ \\
10 & How many times do you eat rice with side dish daily? & $2.98 \pm 0.795$ \\
\hline
\end{tabular}


Table 4. Practice of Mothers $(n=96)$

\begin{tabular}{lc}
\hline \multicolumn{1}{c}{ Questions } & Yes (\%) \\
\hline I give my child vegetables everyday & 82.3 \\
Does a child need money to buy food? & 71.9 \\
A child need breakfast before leaving for school & 96.9 \\
Does your child bring food to school? & 85.4 \\
Do you give advice about food to buy to your child? & 99 \\
\hline
\end{tabular}

Table 5. Mother Advices to Their Children when Buying Snack Food

\begin{tabular}{lc}
\hline \multicolumn{1}{c}{ Mother Advice } & $\%$ \\
\hline Don't buy contaminated hazard food (contain MSG, food preservatives, artificial color, mycroorganism) & 78.4 \\
Buy hygienic food, nutritious and healthy food & 38.4 \\
About food safety & 12.1 \\
Don't buy drink that contain iced cubes & 8.1 \\
Read food expired date & 4.0 \\
\hline
\end{tabular}

\section{School Children Knowledge and Attitude.}

Most of school children (92\%) recognize that a symbol or figure of balance diet (food pyramid) as a symbol of 4 health and 5 perfect. This condition is supposed that the figure has been introducing by teacher at school or by mother at home. Four healths and 5 perfect concepts is still used as one topic in science lecture. (Source: Science Book for $5^{\text {th }}$ grade, published by Erlangga). Table 6 shows generally school children have good nutritional knowledge. Question about variety of food can be answered correctly by more than $64 \%$ students, but when the concept was asking using negative statement, that is no single food has complete nutrient, only $16 \%$ answered correct- ly. This shows that positive question form is better understand by the children. The question of rice can be replaced by noodles, can only be answered correctly by $31 \%$ students indicating.

\section{Relationship Between Practice and Attitude}

Most of school children (95\%) realize that both eat fruits everyday is better and eat vegetable 2-3 times/day. They (87\%) also realize that there is no need to eat a lot of sugar or sweet foods. Furthermore they realize that both breakfast will make them easier to learn and walking is healthier than travelling by vehicle (Table 7).

Table 6. Knowledge of School Children $(n=100)$

\begin{tabular}{lc}
\hline \multicolumn{1}{c}{ Questions } & Yes answer (\%) \\
\hline Healthy 4, Perfect 5 & 92 \\
Variety of food everyday & 64 \\
No single food has complete nutrient & 16 \\
Eat a lot of fat and oil is not necessary & 87 \\
Rice can be replaced by noodles & 31 \\
Rice can be replaced by sticky rice & 78 \\
Eat spinach or kangkung is better than cabbage & 77 \\
Seafood make children smart & 91 \\
Salty fish is better than fresh fish & 14 \\
Egg is as good as chicken & 85 \\
Tempe is as good as chicken & 56 \\
Nuts like mungbeans, redbeans, soybeans and peanuts are good for health & 91 \\
Sweetener is as good as sugar & 19 \\
Drink water at least 4-5 glasses per day & 68 \\
Think that drinking milk alone is sufficient to make people healthy & 55 \\
Fruits rich of vitamin & 99 \\
Cheap fruits like banana, papaya, are not rich in vitamin & 89 \\
\hline
\end{tabular}


Table 7. Attitude of School Children $(n=100)$

\begin{tabular}{lc}
\hline \multicolumn{1}{c}{ Questions } & Agree (\%) \\
\hline There is no need to eat lots of sugar or sweet food & 87 \\
Eat fruits everyday is better & 95 \\
Rice can be replaced by corn & 79 \\
Rice can be replaced by bread & 87 \\
Rice can be replaced by sweet potato/cassava & 79 \\
Eat vegetable 2-3 times/day & 95 \\
Cucumber is better than carrot & 22 \\
Eat fruit 2 times per week & 38 \\
Seafood is as good as meet & 85 \\
Eat fish can cause worm infestations & 56 \\
Seafood as good as tempe & 60 \\
If drink milk no need for other food & 29 \\
Always drink sweet drinks good for health & 14 \\
Not drink sufficient water can make you sick & 82 \\
Exercise once a week is sufficient & 43 \\
Walking is healthier than travelling by vehicle. & 96 \\
Breakfast will make you easier to learn & 98 \\
\hline
\end{tabular}

\section{CONCLUSION}

School children from middle class in urban Bogor have relatively good food habits which were supported by mother behavior. This study found no relationship between family socioeconomic and nutritional status on school children food habit.

\section{ACKNOWLEDGEMENT}

Thank you for Directorate of Higher Education, Ministry of Education through SIBERMAS Loan 2009, Bogor District Government and SDN Gunung Gede Bogor for supporting this research.

\section{REFERENCES}

[MOH] Ministry of Health. 2007. National Basic Health Report (Riskesdas). Ministry of Health Republic of Indonesia, Jakarta.

[WHO] World Health Organization. 2009. WHO AnthroPlus for personal computers Manual: Software for assessing growth of the world's children and adolescents. WHO, Geneva. (http://www.who.int/growth ref/tools/en/). 